\title{
CORRIGENDUM
}

\section{Schizophrenia genes, gene expression, and neuropathology: on the matter of their convergence}

PJ Harrison and DR Weinberger

Molecular Psychiatry (2005) 10, 804. doi:10.1038/sj.mp.4001686

Correction to: Molecular Psychiatry (2005) 10, 420. doi:10.1038/sj.mp.4001630

Following the publication of the above corrigendum, the authors found it necessary to further clarify the correction from Molecular Psychiatry (2005), 10, 40-68: on the sixth page, in the left hand column, 10 lines from the bottom, the sentence should read: '... such that Met-COMT has significantly lower enzyme activity than val-COMT'. 